\title{
The syntax and semantics of Danish quantity genitives
}

\section{PER ANKER JENSEN}

Whereas determiner genitives have received extensive attention over the past many years, quantity genitives like en to meters fiskestang (lit. 'a two meter's fishing rod') and en tre retters menu (lit. 'a three courses' menu'). have been a rather neglected subject.

This paper presents an integrated theory of the syntax (including topology) and the semantic composition of Danish quantity genitives. As my point of departure, particular attention is paid to Mikkelsen's (1911) and Hansen \& Heltoft's (2011) analyses in Dansk ordföjningslare and Grammatik over det danske sprog (GDS), respectively. Mikkelsen's conceptual approach to the analysis of Danish genitives is very insightful semantically and argued to be supported on independent syntactic grounds. On the other hand, the analysis of quantity genitives in GDS is shown to be untenable semantically as well as topologically.

The integrated theory proposed in this paper argues that quantity genitives are distributionally equivalent to attributive Adjective Phrases and comprise two subtypes, 'measure genitives' and 'constitutive genitives'. These two subtypes are identical as regards syntactic structure, and both are followed by the indefinite form of attributive adjectives. This distinguishes them clearly from determiner genitives, which require the definite form of the adjective. But the two subtypes of quantity genitives differ semantically in crucial respects. Measure genitives denote only measure, whereas constitutive genitives also denote a meronymic relation between the two nominals involved. This relates constitutive genitives semantically to determiner genitives. However, they are distinct in that the latter have the whole-denoting nominal as part of the genitive, whereas constitutive genitives have the part-denoting nominal as part of the genitive.

The underlying theoretical foundation of the paper is feature-based syntax and formal semantics enhanced with generative-lexicon qualia structure. 